\title{
Platelet aggregation and incident ischaemic heart disease in the Caerphilly cohort
}

\author{
P C Elwood, S Renaud, A D Beswick, J R O’Brien, P M Sweetnam
}

\begin{abstract}
Background-Platelets are involved in myocardial infarction but evidence of prediction of infarction by measures of platelet function are sparce.

Methods-Platelet aggregation to thrombin and to ADP in platelet rich plasma was recorded for 2176 men aged 49-65 years in the Caerphilly cohort study. Results-Results from 364 men were excluded, 80 of whom had not fasted before venepuncture; most of the others were excluded because antiplatelet medication had been taken shortly before the platelet tests. During the five years following the platelet tests 113 ischaemic heart disease (IHD) events which fulfilled the World Health Organisation criteria were identified-42 fatal and 71 non-fatal. No measure of platelet aggregation was found to be significantly predictive of incident IHD. The possibility that platelet function is predictive for only a limited time after it is characterised, and that prediction falls off with time, was tested. When IHD events are grouped by their time of occurrence after aggregation had been measured, the test results show a gradient suggestive of prediction of early IHD events. Thus, $24 \%$ of the men who had an event within $\mathbf{5 0 0}$ days of the test had had a high secondary response to ADP while only $12 \%$ of those whose IHD event had been 1000 or more days after the test had shown a high platelet response at baseline. The trend in these proportions is not significant.
\end{abstract}

Conclusions-Platelet aggregation to thrombin and ADP in platelet rich plasma was recorded in the Caerphilly cohort study. No measure of aggregation was found to be predictive of IHD.

(Heart 1998;80:578-582)

Keywords: platelet aggregation; ischaemic heart disease; prediction

Evidence that platelets play a key role in ischaemic heart disease (IHD) comes from a wide variety of sources, including the histology of thrombi in the coronary vessels, ${ }^{1}$ the finding of platelet emboli in the microcirculation of the myocardium after sudden death, ${ }^{2}$ and the finding of an occlusive thrombus on angiography shortly after infarction. ${ }^{3}$ Animal studies confirm that platelet aggregates develop if the coronary vessel intima is damaged. ${ }^{4} \mathrm{~A}$ few case control studies show that platelet aggregation is enhanced after myocardial infarction ${ }^{5-7}$ and cross sectional evidence shows an association between aggregation and prevalent IHD. ${ }^{89}$

Further suggestive evidence of the relevance of platelets to myocardial infarction comes from the comparability of the diurnal patterns in aggregation and infarction, ${ }^{10}$ and from significant relations between platelet aggregation and certain risk factors for IHD. ${ }^{11}$ In addition, it has been reported that patients who died after a myocardial infarct had had larger, and therefore more active, platelets than those who survived. ${ }^{12}$ On the basis of a strong negative relation between alcohol intake and platelet aggregation, ${ }^{13}$ Renaud went on to suggest that a lower platelet sensitivity, through the consumption of red wine, may explain the reduced IHD mortality in France-the so called "French paradox". ${ }^{14}$

The most persuasive evidence that platelet function is relevant to infarction comes, however, from trials of aspirin, in which a small dose of aspirin, sufficient to modify platelet aggregation, is associated with a $25-35 \%$ reduction in IHD incidence. ${ }^{15} 16$

Only two studies of the prediction of platelet aggregation for IHD appear to have been reported. These were both relatively small studies yet they detected significant prediction of coronary events and mortality in survivors of a myocardial infarct ${ }^{17}$ and in healthy men. ${ }^{18}$

We report here data from an ad hoc study of platelet aggregation and incident IHD in the Caerphilly cohort study. ${ }^{19}$ The work was approved by the South Glamorgan ethics committee, and all subjects gave informed signed consent.

\section{Methods}

SUBJECT

The Caerphilly cohort of 2512 men aged 45-59 years had been identified during the period 1979 to $1983 .{ }^{19}$ In the first reexamination of the men (phase II) five years later, tests of platelet aggregation were performed.

Men were seen at an afternoon/evening clinic for the collection of general data, including evidence of prevalent or past IHD. Each man was then asked to attend an early morning clinic, after an overnight fast, for venepuncture; for most the blood was taken between 06:00 and 09:00. The first $30 \mathrm{ml}$ of blood taken was used for other tests, and the following $18 \mathrm{ml}$ was drawn without stasis into $2 \mathrm{ml}$ of fresh $0.13 \mathrm{M}$ sodium citritate for the preparation of platelet rich plasma (PRP). Samples were kept at $30^{\circ} \mathrm{C}$ in a water bath and were spun within 10 minutes, at $3000 \mathrm{rpm}$ for 10 minutes. Some of the plasma was removed, the sample spun 
again and the resultant platelet poor plasma (PPP) used to adjust the platelet count in the PRP to 300000 platelets $/ \mu \mathrm{m}$. The preparation of the PRP and the measurements of aggregation were all completed within 30 minutes of venepuncture, with an absolute maximum delay in a very few samples of 120 minutes.

PLATELET TESTS

The tests, equipment, and reagents have been described in detail elsewhere. ${ }^{9}$ In brief, platelets were tested in Rubel-Renaud coaguloaggregometers with ADP (Sigma Chemical Co, St Louis, Missouri, USA; $0.725 \mu \mathrm{M} / 1$ in PRP) and thrombin (Sigma Chemical Co; 0.056 units $/ \mathrm{ml}$ in PRP), and all the tests were done in duplicate. Because of the number of tests done, many batches of ADP and thrombin had to be used. Efforts were made within the laboratory to standardise each new batch against the current batch; in addition, possible remaining batch to batch differences were allowed for statistically by including a factor for "batch" in the analyses. Samples of PRP were exposed to agonists and changes in optical density recorded. The optical density of PPP was also measured so that responses could be stated as both an absolute change and a change proportional to the PRP-PPP difference.

No single measurement could adequately characterise the changes in the optical density of a platelet suspension, as traced by a pen recorder. We therefore made a number of measurements of the recorded tracings. Some of these had been used in our earlier reports, ${ }^{9} 13$ but to these were added several further measurements made on the pen recorder tracings. We made numerous measurements on the traces for the various agonists. We then examined the reproducibility between the duplicates of each of these, how well each discriminated between subjects, and to what extent they correlated with other measurements. On the basis of this we selected a number of measurements that appeared to be different aspects of platelet function and were largely independent of other measurements. The following indices of platelet aggregation are therefore used.

For the response to thrombin:

- the maximum increase in optical density following exposure to thrombin

- the time from the addition of thrombin, to the point at which the disaggregation, which followed aggregation, became maximal.

For the primary response to ADP:

- the maximum increase in optical density during the primary response

- the extent of recovery after the primary response.

For the secondary response to ADP:

- the increase in optical density during the secondary reponse at a fixed point exactly two minutes after exposure to ADP

- the pattern of the secondary response judged visually and graded as follows (where there was a difference between the duplicate traces, the higher of the two grades was used):

(1) little primary or secondary aggregation
(2) marked primary, little secondary aggregation

(3) slight secondary aggregation

(4) two peaks, primary greater than secondary

(5) slight primary, secondary plateau or increasing

(6) two peaks, secondary greater than primary

(7) marked primary into secondary

(8) primary and secondary form a continuous response.

As with previous work, ${ }^{9}{ }^{20}$ the results are presented with the indices expressed as percentages of the maximum possible aggregation, except for the time to maximum recovery for thrombin aggregation. In the analysis the effect of using absolute changes and of allowing for differences in the original platelet count were investigated. Neither made any material difference.

Primary responses to ADP and the responses to thrombin are unimodal, ${ }^{9}$ and are treated as statistically normal. The distribution of the secondary reponses to ADP seems to be bimodal $^{9}$ and, as before, was dichotomised into "high" and "low" responders.

INCIDENT DISEASE

Evidence on IHD events during the five years following the baseline platelet tests was obtained from death certificates, from hospital records, and from repeated ECGs. The criteria for a clinical event are based on the standard World Health Organisation definitions, and are described in detail elsewhere. ${ }^{21}$

\section{Results}

The cohort at the time of the first reexamination comprised 2398 men aged 49-65 years. Tests of platelet aggregation were performed on 2176 (90.7\%) of these. Fasting blood was not obtained from 80 men. The results from these were excluded, together with those of a further 284 men who had taken an antiplatelet drug during the previous seven days. The five year incidence of IHD in the men excluded because of non-fasting or antiplatelet medication was considerably higher $(10.2 \%)$ than in the total cohort $(6.7 \%)$. Satisfactory data were obtained from 1809 men for aggregation to $\mathrm{ADP}$ and from 1812 men to thrombin (table 1).

During the five years following the baseline examination 113 IHD events occurred among the 1812 men with a satisfactory measurement of aggregation, $42(37 \%)$ of which were fatal. The predictive power of the aggregation tests for these events is examined below. In order to

Table 1 Numbers of men in the cohort, numbers excluded, and incidence of IHD

\begin{tabular}{|c|c|c|}
\hline & $\begin{array}{l}\text { Total } \\
\text { number } \\
\text { of men }\end{array}$ & $\begin{array}{l}\text { Number (\%) } \\
\text { of men who } \\
\text { experienced an } \\
\text { incident IHD } \\
\text { event }\end{array}$ \\
\hline Total cohort & 2398 & $161(6.7 \%)$ \\
\hline \multicolumn{3}{|l|}{ Exclusions } \\
\hline No platelet function tests & 222 & $11(5.0 \%)$ \\
\hline Not fasting & 80 & $9(11.3 \%)$ \\
\hline Antiplatelet drugs in previous week & 284 & $28(9.9 \%)$ \\
\hline \multicolumn{3}{|l|}{ Inclusions } \\
\hline With thrombin results & 1812 & $113(6.2 \%)$ \\
\hline With ADP results & 1809 & $113(6.2 \%)$ \\
\hline
\end{tabular}


Table 2 Response to thrombin. Mean (SD) change in optical density on exposure of platelet rich plasma to thrombin, and time to maximum recovery after aggregation, in men who went on to experience an IHD event and in those who experienced no such event during the subsequent five years

\begin{tabular}{lll}
\hline & $\begin{array}{l}\text { Men who experienced } \\
\text { no incident IHD event }\end{array}$ & $\begin{array}{l}\text { Men who experienced } \\
\text { an incident IHD event }\end{array}$ \\
\hline Five year incidence & $\mathrm{n}=1699$ & $\mathrm{n}=113$ \\
$\quad$ Maximum aggregation & $10.43(5.64)$ & $9.87(5.27) \mathrm{p}=0.31$ \\
Time to maximum recovery (minutes) & $2.47(0.48)$ & $2.52(0.48) \mathrm{p}=0.30$ \\
1000 day IHD incidence & $\mathrm{n}=1699$ & $\mathrm{n}=48$ \\
$\quad$ Maximum aggregation & $10.43(5.64)$ & $9.58(5.88) \mathrm{p}=0.31$ \\
Time to maximum recovery (minutes) & $2.47(0.48)$ & $2.53(0.49) \mathrm{p}=0.45$ \\
\hline
\end{tabular}

Table 3 Primary response to ADP. Mean (SD) change in optical density during the primary wave of aggregation on exposure to ADP and the degree of recovery before the secondary wave of aggregation commenced

\begin{tabular}{lll}
\hline & $\begin{array}{l}\text { Men who experienced no } \\
\text { incident IHD event }\end{array}$ & $\begin{array}{l}\text { Men who experienced an } \\
\text { incident IHD event }\end{array}$ \\
\hline Five year incidence & $\mathrm{n}=1696$ & $\mathrm{n}=113$ \\
Maximum aggregation & $24.92(7.76)$ & $25.43(7.45) \mathrm{p}=0.50$ \\
Recovery & $7.80(4.68)$ & $7.71(5.00) \mathrm{p}=0.84$ \\
1000 day IHD incidence & $\mathrm{n}=1696$ & $\mathrm{n}=48$ \\
Maximum aggregation & $24.92(7.76)$ & $25.29(8.11) \mathrm{p}=0.74$ \\
Recovery & $7.80(4.68)$ & $6.96(5.36) \mathrm{p}=0.22$ \\
\hline
\end{tabular}

examine the possibility that prediction might fall off with time, we also examined aggregation in men who had an incident IHD event within various intervals after the baseline tests (less than 500 days, 500 to 999 days, and so on).

Table 2 summarises the data for aggregation to thrombin. Both the mean decrease in optical density and the time to maximum recovery after aggregation are virtually identical in the 113 men who experienced an IHD event and the men who did not. Furthermore, there is no evidence of significant differences in aggregation in the men who experienced an IHD event within 1000 days (approximately three years) of the tests. Standardisation for various combinations of smoking habit, time since last cigarette, and alcohol consumption had virtually no effect.

Table 3 shows the same data for the primary response to ADP. Again there is no evidence of any prediction, either for IHD events within the five years, or within the first three years of follow up. Standardisation for possible confounding by smoking and alcohol consumption made virtually no difference.

Earlier work on prevalent IHD ${ }^{9}$ had shown that the aspect of aggregation which appeared to be most closely associated with prevalent IHD was secondary aggregation to ADP. The results for this test were therefore examined closely. Table 4 shows that among the men who had shown a high response to ADP $7.3 \%$ had experienced an incident IHD event during the following five years. This is slightly higher than the proportion among the men who had shown

Table 4 Secondary response to ADP. Numbers of men with a "low" and a "high" secondary response to ADP and the relative odds for an IHD occurring within the men so defined

\begin{tabular}{llll}
\hline & $\begin{array}{l}\text { No incident } \\
\text { IHD event }\end{array}$ & $\begin{array}{l}\text { An incident } \\
\text { IHD event }\end{array}$ & $\begin{array}{l}\text { Relative odds for an } \\
\text { IHD event }\end{array}$ \\
\hline $\begin{array}{l}\text { Low secondary response } \\
\text { High secondary response }\end{array}$ & 1467 & $95(6.1 \%)$ & 1.0 \\
& 229 & $18(7.3 \%)$ & $1.21(0.72$ to 2.05) \\
\hline
\end{tabular}

Table 5 Secondary ADP response and time to an incident IHD event. Numbers of men who had an IHD event within various time periods after the platelet tests had been conducted

\begin{tabular}{lcc}
\hline & $\begin{array}{l}\text { Number of } \\
\text { men }\end{array}$ & $\begin{array}{l}\text { Number who had } \\
\text { shown a high } \\
\text { secondary response }\end{array}$ \\
\hline $\begin{array}{l}\text { No incident IHD event } \\
\text { An IHD event within }\end{array}$ & 1696 & $229(14 \%)$ \\
500 days & 25 & $6(24 \%)$ \\
$500-999$ days & 23 & $5(22 \%)$ \\
$1000-1499$ days & 30 & $5(17 \%)$ \\
1500 days or longer & 20 & $1(5 \%)$ \\
Unknown time* & 15 & $1(7 \%)$
\end{tabular}

${ }^{\star}$ Men with an ECG defined event and no symptomatic event.

less active responses to $\mathrm{ADP},(6.1 \%)$ but the difference is not significant. The odds of an event in these men, compared to men with a low response, was 1.21 (not significant), and standardisation of this for possible confounding makes little difference.

Table 5 displays these secondary responses to ADP grouped by the time after the tests within which the IHD events had occurred. There is a suggestion of a gradient in that, of the men who had an IHD event within 500 days after the platelet test, $24 \%$ had shown a high response to ADP and this proportion decreased steadily, with only $12 \%$ of those whose IHD event occurred 1000 or more days after the test having had a high response. A log rank test to compare the time pattern of incident IHD in "low" and "high" secondary ADP response groups yields a $\chi^{2}(1$ degree of freedom) of $1.25(\mathrm{p}=0.26)$.

There was very great variability in the pattern of the waves of secondary aggregation to ADP. Table 6 displays the numbers who had shown various patterns, as judged by eye. It would have seemed reasonable to have predicted that a marked secondary wave would be predictive - that is, the patterns 6,7 , and 8 as we had defined them. Men with these patterns, however, show no stronger prediction than the others.

\section{Discussion}

We have failed to show any useful prediction of IHD by platelet aggregation to a number of agonists, including ADP. The only possible exception arises from a post hoc examination of the secondary response to ADP and early

Table 6 Pattern of secondary response to ADP

\begin{tabular}{lcc}
\hline Pattern type & Number of men & $\begin{array}{l}\text { Number who } \\
\text { experienced an } \\
\text { incident IHD event }\end{array}$ \\
\hline 1 & 9 & 0 \\
2 & 69 & $7(10 \%)$ \\
3 & 578 & $34(6 \%)$ \\
4 & 591 & $39(7 \%)$ \\
5 & 17 & $1(6 \%)$ \\
6 & 235 & $11(5 \%)$ \\
7 & 265 & $19(7 \%)$ \\
8 & 41 & $2(5 \%)$ \\
All patterns & 1805 & $113(6.3 \%)$
\end{tabular}

1, little primary or secondary aggregation; 2, marked primary, little secondary aggregation; 3 , slight secondary aggregation; 4 , two peaks, primary greater than secondary aggregation; 5 , slight primary aggregation, secondary plateau or increasing; 6 , two peaks, secondary greater than primary aggregation; 7 , marked primary into secondary aggregration; 8 , primary and secondary aggregation form a continuous response. 
IHD events (table 5). We regard this as special pleading, as a distinction between early and later IHD events had not been part of our original intentions. However, the time to infarction should perhaps be considered in any future examination of prediction by platelet aggregation.

Two studies have shown significant prediction from platelet aggregation. Trip et al recorded spontaneous platelet aggregationthat is, aggregation occurring on stirring PRP, without the addition of any agonist. ${ }^{17}$ During a five year follow up of 149 postinfarction patients there was a strong relation with the incidence of IHD events; the 26 patients who had shown definite spontaneous aggregation had a relative risk of death of 5.4, and a relative risk for an IHD event of 3.1, relative to the 94 patients who had shown no spontaneous aggregation (both significant). On the other hand, Thaulow et al examined prediction by aggregation to $\mathrm{ADP}$, adrenaline, and collagen in 487 healthy men aged $40-59$ years. ${ }^{18}$ No significant prediction was observed for adrenaline or collagen, but the 75 men with the fastest ADP induced aggregation rates had significantly higher coronary heart disease mortality than the 75 men with the slowest aggregation $(\mathrm{p}<0.01)$.

We did not measure spontaneous aggregations, nor did we measure the time to incipient ADP aggregation as done by Thaulow et al. ${ }^{18}$ In our hands the time between exposure to an agonist and the commencement was so short that it was almost unmeasurable. On the other hand, as described earlier, we made numerous measurements on the traces from each agonist, and we examined prediction by all those that appeared to give independent and reproducible evidence on the platelet response.

Uncertainty may arise from our method of estimation of aggregation, in particular the use of a single dose of each agonist. The recording of aggregration is difficult and time consuming and, because of our desire to do the tests with fasting blood, it was only possible to complete all the tests in duplicate on six subjects each morning. It was therefore assumed that the best use of resources would be to record responses to single doses of each agonist in the belief that a single measurement on a large cohort would enable prediction to be tested more efficiently than multiple estimates made with different doses of agonists, on a smaller number of subjects. We have no evidence to judge whether we were wrong in this assumption.

We would judge, however, that the techniques we used are reasonable and the results they produced meaningful. The platelet aggregation results, which are the subject of this report, were found to show strong and significant relations between the responses to ADP and alcohol intake. ${ }^{13}$ In another study in which we used precisely these techniques we detected significantly reduced secondary ADP aggregation in subjects whose fat intake had been modified. ${ }^{22}$ Using the same techniques and apparatus, one of us (SR) found differences in aggregation in subjects living in regions with differing rates of coronary heart disease. ${ }^{23}$ These results would seem to remove most of the doubt as to the appropriateness of the aggregation techniques used by us.

The study may have lost some power because of exclusions. The aggregation results for 284 men, many of whom had been on aspirin, were omitted, together with the results for 80 men who had not fasted before venesection. The IHD incidences in these men were $9.9 \%$ and $11.3 \%$, respectively, and both these are significantly greater than the proportion of the other men who experienced an IHD event. This implies that the results of some of the men at greatest risk of IHD, and possibly with the most active platelets, were omitted. Although this was outside our control, the omission of these men represents bias. At the same time, it would seem unlikely that any worthwhile predictive effect would have been totally missed because of these exclusions.

More fundamental uncertainties arise, however, from uncertainties as to the relevance of any in vitro test to platelet function in vivo. The characterisation of a physiological function is clearly very different from the simple measurement of the concentration of a haemostatic or other factor involved in health or disease. In the case of platelets, the preparation of PRP may change the platelets, and exposure to a single agonist within a test tube may inadequately mimic what happens around an atherosclerotic plaque in a coronary vessel. No acceptable experimental approach can avoid all these unrealities, though animal models such as that developed by Folts and his colleagues, in which a coronary artery of a dog is experimentally damaged, ${ }^{4}{ }^{24}$ may approach the real life situation.

One approach which removes some of the unrealities in the PRP tests is to use whole blood. We have included such a test in a later examination of the same cohort ${ }^{8}$ and evaluation against incident IHD events will become possible in a few years. A pilot run of this test was, however, undertaken on a small sample of 308 men seen towards the end of the examinations described in this report, and the methods used and a preliminary examination of the results has already been published. ${ }^{11}$ Results of this test, done with ADP, correlates only poorly with the test done with ADP on PRP from the same men $(r=0.22)$, suggesting that the two approaches, using PRP and whole blood, may reflect different aspects of in vivo platelet function. Evaluation of this test against incident IHD will be of interest.

A measure of platelet activity which is predictive of IHD events could be of very great value in clinical practice. Low dose aspirin is an effective prophylactic against thromboembolic conditions and this is believed to be through its antiplatelet action. A test of platelet function could therefore be used as a screening procedure which might enable low dose aspirin prophylaxis to be targeted towards patients found to have more highly reactive platelets. Furthermore, an approach along these lines might be used to enhance the power of trials to evaluate primary prevention by aspirin. 
The present data provide no convincing evidence that a single measure of platelet aggregation, as it was done under "field" conditions in the Caerphilly study, is relevant to IHD events which occur later.

The work described was supported by the UK Medical Research Council.

1 Davies MJ, Thomas A. Thrombosis and acute coronary artery lesions in sudden cardiac ischemic death. $N$ Engl $f$ Med 1984;310:1137-40.

2 Haerem JW. Platelet aggregates and mural micro-thrombi in the early stages of acute fatal coronary disease. Thromb Res 1974;5:243-9.

3 Dewood MA, Spores J, Notske R, et al. Prevalence of total coronary occlusion during the early hours of transmural myocardial infarction. $N$ Engl F Med 1980;303:897-902.

4 Folts J. An in vivo model of experimental arterial stenosis, intimal damage, and periodic thrombosis. Circulation 1991; 83:IV-3-14.

5 Dreyfus F, Zahavi J. Adenosine diphosphate induced platelet aggregation in myocardial infarction and ischemic heart disease. Atherosclerosis 1973;17:107-20.

6 Vilen L, Johansson S, Kuttl J, et al. ADP-induced platelet aggregation in young female survivors of acute myocardial infarction and their female controls. Acta Med Scand 1985 217:9-13.

7 Rubenfire M, Blevins RD, Barnhart M, et al. Platelet hyperaggregability in patients with chest pain and angiographically normal coronary arteries. Am f Cardiol 1986;57:65760.

8 Elwood PC, Beswick AD, Sharp DS, et al. Whole blood impedance platelet aggregometry and ischemic heart disease. The Caerphilly collaborative heart disease study. Arteriosclerosis 1990;10:1032-6.

9 Elwood PC, Renaud S, Sharp DS, et al. Ischaemic heart disease and platelet aggregation: the Caerphilly collaborative heart diseas study. Circulation 1991;83:38-44.

10 Tofler GH, Brezinski D, Schafer AI, et al. Concurrent morning increase in platelet aggregability and the risk of myocardial infarction and sudden cardiac death. $N$ Engl $\mathcal{F}$ Med 1987;316:1514-18.
11 Sharp DS, Beswick AD, O'Brien JR, et al. The association of platelet and red cell count with platelet impedance changes in whole blood and light-scattering changes in platelet rich
plasma: evidence from the Caerphilly collaborative heart plasma: evidence from the Caerphilly collabora

12 Martin JF, Bath PMW, Burr ML. Influence of platelet size on outcome after myocardial infarction. Lancet 1991;338 1409-11.

13 Renaud SC, Beswick AD, Fehily AM, et al. Alcohol and platelet aggregation: the Caerphilly prospective heart disease study. Am f Clin Nutr 1992;55:1012-17.

14 Renaud S, de Lorgeril M. Wine, alcohol, platelets and the French paradox for coronary heart disease. Lancet 1992;339:1523-6.

15 Elwood PC, Cochrane AL, Burr ML, et al. A randomized controlled trial of acetyl salicylic acid in the secondary prevention of mortality from myocardial infarction. BMf 1974;i:436-40.

16 Antiplatelet Trialists' Collaboration. Collaborative overview of random trials of anti-platelet therapy. 1. Prevention of death, myocardial infarction and stroke by prolonged antiplatelet therapy in various categories of patients. BMF platelet therapy in

17 Trip MD, Cats VM, Van Capelle FJL, et al. Platelet hyperreactivity and prognosis in survivors of myocardial-infarction. N Engl f Med 1990;322:1549-54.

18 Thaulow E, Erikssen J, Sandvik L, et al. Blood platelet count and function are related to total and cardiovascular death in apparantly healthy men. Circulation 1991;84:613-17.

19 The Caerphilly and Speedwell Collaborative Group. Caerphilly and Speedwell collaborative heart disease studies. $\mathcal{F}$ Epidemiol Community Health 1984;38:259-62.

20 Elwood PC, Beswick AD, O'Brien JR, et al. Interrelationships between haemostatic tests and the effects of some dietary determinants in the Caerphilly cohort of older men. Blood Coagul Fibrinolysis 1993;4:529-36.

21 Yarnell JWG, Baker IA, Sweetnam PM, et al. Fibrinogen, viscosity, and white blood cell count are major risk factors for ischemic heart disease. The Caerphilly and Speedwell collaborative heart disease studies. Circulation 1991;83: 836-44.

22 Beswick AD, Fehily AM, Sharp DS, et al. Long-term diet modification and platelet activity. F Intern Med 1991;229: 511-15.

23 Renaud S, Dumont E, Godsey F, et al. Platelet function in relation to dietary fats in farmers from two regions of France. Thromb Haemost 1979;40:518-31.

24 Folts JD, Gallagher K, Rowe GG. Blood flow reductions in stenosed canine coronary arteries: vasospasm or platelet aggregation? Circulation 1982;65:248-55. 